\title{
Gene Expression of Circulating Tumour Cells and Its Correlation with Tumour Stage in Breast Cancer Patients
}

\author{
E. Bölke ${ }^{1}$, K. Orth 2 , P. A. Gerber ${ }^{3}$, G. Lammering ${ }^{4}$, R. Mota ${ }^{3}$, M. Peiper ${ }^{5}$, C. Matuschek ${ }^{1}$, W. Budach ${ }^{1}$, \\ E. Rusnak ${ }^{6}$, S. Shaikh 7 , B. Dogan ${ }^{8}$, H. B. Prisack ${ }^{8}$, H. Bojar ${ }^{8}$ \\ ${ }^{1}$ Department of Radiation Therapy and Radiation Oncology, University of Düsseldorf, Germany, \\ ${ }^{2}$ Department of Surgery, KH Emden, Germany, \\ ${ }^{3}$ Department of Dermatology, University of Düsseldorf, Germany, \\ ${ }^{4}$ Maastro Clinic, Radiation Oncology, Maastricht, The Netherlands, \\ ${ }^{5}$ Department of Surgey, University of Düsseldorf, Germany, \\ ${ }^{6}$ Department of Anesthesiology, State University of New York at Buffalo, USA, \\ ${ }^{7}$ Department of Anesthesiology UMass Memorial Medical Center Worcester, USA, \\ ${ }^{8}$ Department of Clinical Oncology, University of Düsseldorf, Germany
}

\begin{abstract}
Background: Breast cancer (BC) represents one of the leading causes of cancer related deaths worldwide. New tools for diagnostic staging and therapeutic monitoring are needed to improve individualized therapies and improve clinical outcome. The analyses of circulating tumour cells may provide important prognostic information in the clinical setting.

Materials and Methods: Circulating tumour cells (CTC) of $63 \mathrm{BC}$ patients were isolated from peripheral blood (PB) through immunomagnetic separation. Subsequently, RT-PCR or mPCR for the genes ga733.2, muc-1, c-erbB2, mgb-1, spdef and c-erbB2 were performed. Subsequently, expression data were correlated with the tumour stages. Fourteen healthy individuals served as controls.

Results: Significant correlations with tumour stages were found in single gene analyses of ga733.2, muc-1 and in multi-gene analyses of ga733.2/ muc-1/ mgb1/ spdef. Furthermore, a significant correlation of $\mathrm{Ca}$ 15-3 and all studied genes was also observed.

Conclusion: Herein, we demonstrated a positive correlation of a gene signature consisting of ga733.2, muc-1, $m g b 1$ and spdef and advanced stages of BC. Moreover, all studied genes and gene patterns revealed a significant correlation with $C$ a $15-3$ positive cases.
\end{abstract}

Key words: Mamma carcinoma, gene signature, realtime-PCR

Abbreviations: $\mathrm{BC}=$ breast cancer; $\mathrm{CTC}=$ circulating tumour cells; $\mathrm{PB}=$ peripheral blood; $c$-erbB2 = cellular avian erythroblastosis homologue B2; ga733.2 = major gastrointestinal tumour-associated protein; muc-1 = mucin-1; mgb-1 = mammaglobin-typ1; $\mathrm{mRNA}=$ messenger RNA; PCR = polymerase chain reaction; RT$\mathrm{PCR}=$ reverse transcriptase polymerase chain reaction; RT $=$ reverse transcriptase; $s p d e f=\mathrm{SAM}$ pointed domain-containing ETS transcription factor; FD = First Diagnosis; $\mathrm{MD}=$ Metastatic disease

\section{INTRODUCTION}

Even though new developments in clinical research on breast cancer (BC) have provided clinicians with a set of important diagnostic tools, there is still an urgent need for further, more sensitive staging techniques. Recent studies have shown that quantitative and qualitative analyses of circulating tumour cells (CTC) may provide prognostic information in $\mathrm{BC}[1,2]$. Attempts to isolate CTC in peripheral blood (PB) date back to more than 100 years [3]. Sandberg et al. isolated CTC from $\mathrm{BC}$ patients using centrifugation and fibrinogen to aggregate erythrocytes [4]. Notably, Hsieh et al. reported that the absolute count of CTC may be related to an aggressive course of disease in BC patients [5]. First attempts to isolate CTC through immunomagnetic separation were made by Berois et al using a CK-19 on BC cell lines [6]. This technique was recently successfully used by Hardingham et al. in patients with gastrointestinal neoplasias [7]. Combining immunomagnectic separation and real-time-PCR (RT-PCR), this group could positively correlate the presence of CTC in PB with shorter disease-free intervals.

Gene profile analyses of certain putative genetic markers may lead to sensitive and specific CTC detection and may enable an improvement in the outcome prediction [8-13]. In fact, PCR and RT-PCR can be applied to perform expression analyses of immunomagnectically isolated CTC. In a previous study we analysed the CTC of $63 \mathrm{BC}$ patients in various disease stages and identified the genes ga733.2, muc-1, mgb1 and spdef as putative markers for CTC detection. Based upon our previous data, in this study we performed correlation analyses between the detected gene expression levels and the known clinical staging of breast cancer. Furthermore, we compared the gene expression data with the detected Ca15-3 serum levels. Increased serum levels of the tumour marker Ca 15-3 have been associated with advanced disease and poor outcome in several studies $[14,15]$. 


\section{Materials AND Methods}

Our study population consisted of 63 BC patients and 14 healthy controls. 50 patients with first diagnosed disease (FD) and 13 patients with metastatic disease (MD) in various disease stages were enrolled. All patients provided written informed consent. After peripheral venous blood sampling, CTC were separated using an immunomagnetic method (Adnagen Breast Cancer Select Kit) according to the instructions of the manufacturer (Adnagen). Cell lysates underwent mRNA isolation and reverse transcription following the manufacturer's instructions (Promega). Subsequently, mPCR for the genes ga733.2 and $m u c-1$ and RT-PCR for the genes mgb1 and spdef were performed. The resulting gene profiles were then compared with tumour stage according to the TNM grading system and tumour stage of the American Joint Committee on Cancer (AJCC) [16]. Additionally, CTC profiling was compared to ELISA-determined Ca 15-3 positivity. Correlations were performed either by Pearson's two-sided $\chi^{2}$-test for dichotomized values or by Pearson's bivariate correlation for values with two thresholds. Significance was defined by $p$ $<0.05$.

\section{RESULTS}

\section{Correlation to Disease State}

Single gene expression and gene patterns were correlated to first diagnosed disease (FD) and metastatic disease (MD). Only mgb1 was significantly correlated to $\mathrm{MD}(\mathrm{p}=0.019)$ but not to $\mathrm{FD}$, whereas spdef, muc-1, ga733.2 and c-erbB2 did not correlate with disease stage. Consecutive multiple gene evaluations demonstrated significance for the pattern ga733.2/ muc-1 ( $\mathrm{p}=0.045)$. The gene pattern ga733.2/muc$1 /$ spdef/mgb1 showed a significant correlation with $\mathrm{MD}(\mathrm{p}=0.023)$.

\section{Correlation to Tumour Stage}

Tumour stage was specified according to AJCC guidelines [16]. Since the tumour stage could not be identified in two BC cases, these patients were excluded from the study. Single positivity within the gene pattern ga733.2/ muc-1 was significantly related to advanced disease, with 10 out of 12 positive cases found in level IIIa or higher. Similarly, 11 out of 15 single positive results within the gene pattern ga733.2/ muc-1/mgb1/spdef were observed in level IIIa or higher. Finally, 90\% (9 out of 10) of twofold-positive results within the 4 gene pattern were documented in higher levels $(\mathrm{p}=0.001)$ (Table 1$)$.

\section{Correlation to Nodal Status}

The gene expression profiles were further correlated with nodal status. Lymph node $(\mathrm{N})$ status was not available in 4 patients. They were excluded from further analyses. $\mathrm{N}$ status was stratified in three levels, N0, N1 and $\geq$ N2. Significant correlation was found between ga733.2 ( $\mathrm{p}=0.042$ ) and muc-1 ( $\mathrm{p}=0.039)$ overexpression and higher N-levels. The analyses of spdef, mgb1, ga733.2 and muc-1 did not reveal a significant correlation. Interestingly, two-fold positive results within the gene pattern ga733.2/ muc-1/mgb1/spdef were significant $(p=0.016)$, whereas simple positive results within this gene pattern did not correlate with nodal status (Table 2).

Table 1. Correlation to disease staging. Correlation between gene expression and disease staging. Patients were stratified in groups I, IIa-IIb and IIIa or higher. Simple and twofold positivity of the gene profile ga $733.2 / \mathrm{muc}-1 / \mathrm{mgb1} / \mathrm{spdef}$ are shown (Pearson's bivariate correlation).

\begin{tabular}{|c|c|c|c|c|}
\hline \multirow{2}{*}{ Analyzed gene } & \multicolumn{3}{|c|}{ Disease Staging } & \multirow[b]{2}{*}{$p$-valu } \\
\hline & $I$ & $I I a-I I b$ & $>I I I a$ & \\
\hline ga733.2 & $\begin{array}{c}0 / 18 \\
\%\end{array}$ & $\begin{array}{l}1 / 16 \\
6.3 \%\end{array}$ & $\begin{array}{c}7 / 27 \\
25.9 \%\end{array}$ & 0.009 \\
\hline$m u c-1$ & $\begin{array}{c}0 / 18 \\
\%\end{array}$ & $\begin{array}{l}1 / 16 \\
6.3 \%\end{array}$ & $\begin{array}{c}9 / 27 \\
33.3 \%\end{array}$ & 0.002 \\
\hline spdef & $\begin{array}{c}0 / 17 \\
\%\end{array}$ & $\begin{array}{c}2 / 15 \\
13.3 \%\end{array}$ & $\begin{array}{l}5 / 25 \\
20 \%\end{array}$ & 0.057 \\
\hline$m g b 1$ & $\begin{array}{c}0 / 16 \\
\%\end{array}$ & $\begin{array}{l}1 / 15 \\
6.7 \%\end{array}$ & $\begin{array}{c}4 / 23 \\
17.4 \%\end{array}$ & 0.063 \\
\hline ga $733.2 / m u c-1$ & $\begin{array}{c}0 / 18 \\
\%\end{array}$ & $\begin{array}{c}2 / 16 \\
12.5 \%\end{array}$ & $\begin{array}{c}10 / 27 \\
37 \%\end{array}$ & 0.001 \\
\hline simple positive & $\begin{array}{c}0 / 16 \\
\%\end{array}$ & $\begin{array}{c}4 / 15 \\
26.7 \%\end{array}$ & $\begin{array}{l}11 / 23 \\
47.8 \%\end{array}$ & 0.001 \\
\hline twofold positive & $\begin{array}{c}0 / 16 \\
\%\end{array}$ & $\begin{array}{l}1 / 15 \\
6.7 \%\end{array}$ & $\begin{array}{c}9 / 23 \\
39.1 \%\end{array}$ & 0.001 \\
\hline
\end{tabular}


Table 2. Correlation to nodal status. Correlation between gene expression and nodal status. Patients were stratified in groups N0, N1 and N2 or higher. Simple and twofold positivity of the gene profile ga733.2/muc-1/mgb1/spdef are shown (Pearson's bivariate correlation).

\begin{tabular}{|c|c|c|c|c|}
\hline \multirow{2}{*}{ Analyzed gene } & \multicolumn{3}{|c|}{ Nodal status } & \multirow{2}{*}{ p-value } \\
\hline & No & N1 & $>\mathrm{N} 2$ & \\
\hline \multirow[t]{2}{*}{ ga733.2 } & $1 / 28$ & $4 / 19$ & $3 / 12$ & \multirow{2}{*}{0.042} \\
\hline & $3.6 \%$ & $21.1 \%$ & $25 \%$ & \\
\hline \multirow[t]{2}{*}{$m u c-1$} & $2 / 28$ & $3 / 19$ & $4 / 12$ & \multirow{2}{*}{0.039} \\
\hline & $7.1 \%$ & $15.8 \%$ & $33.3 \%$ & \\
\hline \multirow[t]{2}{*}{$s p d e f$} & $1 / 27$ & $3 / 18$ & $2 / 10$ & \multirow{2}{*}{0.107} \\
\hline & $3.7 \%$ & $16.7 \%$ & $20 \%$ & \\
\hline \multirow[t]{2}{*}{$m g b 1$} & $2 / 26$ & $2 / 17$ & $0 / 9$ & \multirow{2}{*}{0.640} \\
\hline & $7.7 \%$ & $11.8 \%$ & $\%$ & \\
\hline \multirow[t]{2}{*}{$g a 733.2 / m u c-1$} & $2 / 28$ & $5 / 19$ & $4 / 12$ & \multirow{2}{*}{0.034} \\
\hline & $7.1 \%$ & $26.3 \%$ & $33.3 \%$ & \\
\hline \multirow[t]{2}{*}{ simple positive } & $5 / 26$ & $5 / 12$ & $4 / 9$ & \multirow{2}{*}{0.143} \\
\hline & $19.2 \%$ & $41.7 \%$ & $44.4 \%$ & \\
\hline \multirow[t]{2}{*}{ twofold positive } & $1 / 26$ & $5 / 17$ & $3 / 9$ & \multirow{2}{*}{0.016} \\
\hline & $3.8 \%$ & $29.4 \%$ & $33.3 \%$ & \\
\hline
\end{tabular}

Table 3. Correlation to distant metastases. Correlation between gene expression and distant metastases. Patients were stratified in groups M0 or M1. Simple and twofold positivity of the gene profile ga733.2/ muc-1/mgb1/spdef are shown (Pearson's bivariate correlation).

\begin{tabular}{|c|c|c|c|}
\hline \multirow{2}{*}{ Analyzed gene } & \multicolumn{2}{|c|}{ Presence of distant metastases } & \multirow{2}{*}{ p-value } \\
\hline & M0 & M1 & \\
\hline ga733.2 & $\begin{array}{l}4 / 44 \\
9.1 \%\end{array}$ & $\begin{array}{c}4 / 19 \\
21.1 \%\end{array}$ & 0.197 \\
\hline$m u c-1$ & $\begin{array}{l}4 / 44 \\
9.1 \%\end{array}$ & $\begin{array}{c}6 / 19 \\
31.6 \%\end{array}$ & 0.025 \\
\hline spdef & $\begin{array}{l}3 / 39 \\
7.7 \%\end{array}$ & $\begin{array}{c}4 / 19 \\
21.1 \%\end{array}$ & 0.148 \\
\hline$m g b 1$ & $\begin{array}{l}1 / 37 \\
2.7 \%\end{array}$ & $\begin{array}{c}4 / 18 \\
22.2 \%\end{array}$ & 0.018 \\
\hline ga $733.2 / m u c-1$ & $\begin{array}{c}5 / 44 \\
11.4 \%\end{array}$ & $\begin{array}{c}7 / 19 \\
36.8 \%\end{array}$ & 0.018 \\
\hline simple positive & $\begin{array}{c}7 / 37 \\
18.9 \%\end{array}$ & $\begin{array}{c}8 / 18 \\
44.4 \%\end{array}$ & 0.046 \\
\hline twofold positive & $\begin{array}{c}4 / 37 \\
10.8 \%\end{array}$ & $\begin{array}{c}6 / 18 \\
33.3 \%\end{array}$ & 0.063 \\
\hline
\end{tabular}

\section{Correlation to Distant Metastases}

Gene expression profiles were correlated with the presence of distant metastases. muc-1 overexpression was significantly related to metastatic disease $(\mathrm{p}=$ 0.025). Furthermore, 4 out of 5 patients overexpressing $m g b 1$ presented with distant metastases $(\mathrm{p}=0.018)$. Finally, the gene profiles ga733.2/muc-1 ( $\mathrm{p}=0.018)$ and ga733.2/muc-1/spdef / mgb1 ( $\mathrm{p}=0.046)$ significantly correlated with advanced disease (Table 3 ).

\section{Correlation to Ca 15-3 Status}

The gene expression data were also compared with ELISA-determined Ca 15-3 serum levels. Ca 15-3 could not be determined in 4 cases. Positive single gene and gene pattern strongly correlated with $\mathrm{Ca} 15$ 3 positive cases. Statistical analyses revealed highlysignificant results for all genes and gene patterns (Table 4). 
Table 4. Correlation to Ca 15-3. Correlation between gene expression and presence of elevated Ca 15-3 levels in PB. Simple and twofold positivity of the gene profile ga733.2/ muc-1/mgb1/spdef are shown (Pearson's bivariate correlation).

\begin{tabular}{cccc}
\hline Analyzed gene & Ca 15-3 status & positive & p-value \\
& negative & $4 / 9$ & 0.001 \\
\hline ga733.2 & $3 / 50$ & $44.4 \%$ & $<0.001$ \\
muc-1 & $6 \%$ & $5 / 9$ & $<0.001$ \\
spdef & $4 / 50$ & $55.6 \%$ & 0.001 \\
mgb1 & $8 \%$ & $4 / 8$ & $<0.001$ \\
ga $33.2 /$ muc-1 & $4.3 \%$ & $50 \%$ & $<0.001$ \\
simple positive & $1 / 43$ & $3 / 8$ & $<0.001$ \\
\hline
\end{tabular}

\section{Discussion}

Haematological dissemination of malignant cells is a prerequisite to distant organ metastases in many cancer entities [21-24]. Yet, several studies suggest that only a minority of tumour cells have the ability to invade and metastasize [17-19]. Therefore, it is crucial to investigate which genes ultimately facilitate tissue invasion and disease progression.

Here, we propose an association between a certain set of genes (ga733.2, muc-1, mgb1 and spdef) and advanced tumour stages in BC. Notably, the studied gene signature exposed a significant correlation with stage levels IIIa or higher. Herein, muc-1 expression significantly correlated with nodal and distant metastases, and hence higher staging levels. In line with these results, it has been recently shown that a muc-1-induced tumourigenesis gene signature could predict diseasefree and overall survival in patients with breast and lung cancer [20].

All investigated genes and gene profiles were significantly correlated with $C a 15-3$ positivity. Since elevated levels of this tumour marker have been shown to predict the outcome in $\mathrm{BC}$, the gene signature we analyzed is likely to hold prognostic relevance.

The present investigation poses several questions: First, since the analyses was not performed in a prospective manner, it is impossible to determine whether the detected gene profiles in patients with late disease might also be present in early stages of the disease. Second, it remains to be studied whether CTC exhibit a daily or hourly fluctuation in the gene expression levels. This could lead to false negative results in the proposed method.

In summary, our data indicate a notable correlation between the studied genes (ga733.2, muc-1, mgb1 and spdef) and advanced disease in BC. Accordingly, the studied genes might play a role in the process of metastases formation. However, prospective studies in a larger patient population are needed to further validate the proposed hypothesis.

Acknowledgement: This work is dedicated to Kim and Thomas Speer. Furthermore this work is a part of the thesis of Burak Dogan

\section{REFERENCES}

1. Wang L, Wang Y, Liu Y, Cheng M, Wu X, Wei H. Flow cytometric analysis of CK19 expression in the peripheral blood of breast carcinoma patients: relevance for circulating tumor cell detection. J Exp Clin Cancer Res. 2009; 28(1): 57.

2. Cristofanilli M, Hayes DF, Budd GT, et al. Circulating tumor cells: a novel prognostic factor for newly diagnosed metastatic breast cancer. J Clin Oncol. 2005; 23: 1420-30.

3. Ashworth, T.R., A Case of Cancer in which cells similar to those in the tumors were seen in the blood after death. Australian Medical Journal. 1869; 146-148.

4. Sandberg, A.A. and G.E. Moore, Examination of blood for tumor cells. J Natl Cancer Inst, 1957; 19(1): 1-11.

5. Hsieh HB, Marrinucci D, Bethel K, et al. High speed detection of circulating tumor cells. Biosens Bioelectron 2006; 21: 1893-9.

6. Berois N., et al., Detection of rare human breast cancer cells. Comparison of an immunomagnetic separation method with immunocytochemistry and RT-PCR. Anticancer Res. 1997. 17(4A): 2639-46.

7. Hardingham, J.E., et al., Molecular detection of bloodborne epithelial cells in colorectal cancer patients and in patients with benign bowel disease. Int J Cancer. 2000. 89(1): 8-13.

8. Siegel PM, Dankort DL, Hardy WR, Muller WJ. Novel activating mutations in the neu proto-oncogene involved in induction of mammary tumors. Mol Cell Biol. 1994; 14: 7068-77. 
9. Oh JJ, Grosshans DR, Wong SG, Slamon DJ. Identification of differentially expressed genes associated with HER-2/neu overexpression in human breast cancer cells. Nucleic Acids Res. 1999; 27: 4008-17.

10. Siegel PM, Ryan ED, Cardiff RD, Muller WJ. Elevated expression of activated forms of Neu/ErbB-2 and ErbB3 are involved in the induction of mammary tumors in transgenic mice: implications for human breast cancer. Embo J. 1999; 18: 2149-64.

11. Gendler SJ, Lancaster CA, Taylor-Papadimitriou J, et al. Molecular cloning and expression of human tumor-associated polymorphic epithelial mucin. J Biol Chem. 1990; 265: 15286-93.

12. Eltahir EM, Mallinson DS, Birnie GD, Hagan C, George WD, Purushotham AD. Putative markers for the detection of breast carcinoma cells in blood. Br J Cancer. 1998; 77: 1203-7.

13. Lambrechts AC, van 't Veer LJ, Rodenhuis S. The detection of minimal numbers of contaminating epithelial tumor cells in blood or bone marrow: use, limitations and future of RNA-based methods. Ann Oncol. 1998; 9: 1269-76.

14. Pectasides D, Pavlidis N, Gogou L, Antoniou F, Nicolaides C, Tsikalakis D. Clinical value of Ca 15-3, mucinlike carcinoma-associated antigen, tumor polypeptide antigen, and carcinoembryonic antigen in monitoring early breast cancer patients. Am J Clin Oncol. 1996; 19(5): 459-64.

15 Park BW, Oh JW, Kim JH, Park SH, Kim KS, Kim JH, Lee KS. Preoperative Ca 15-3 and CEA serum levels as predictor for breast cancer outcomes. Ann Oncol. 2008;19(4):675-81.

16. Greene FL PD, Fleming ID, et al. . AJCC Cancer Staging Manual. 6th ed. New York: Springer; 2002.

17. Al-Hajj M, Wicha MS, Benito-Hernandez A, Morrison SJ, Clarke MF. Prospective identification of tumorigenic breast cancer cells. Proc Natl Acad Sci U S A. 2003; 100(7): 3983-8.

18. Lapidot T, Sirard C, Vormoor J, Murdoch B, Hoang T, Caceres-Cortes J, Minden M, Paterson B, Caligiuri MA, Dick JE. A cell initiating human acute myeloid leukaemia after transplantation into SCID mice. Nature. 1994; 367(6464): 645-8.
19. Reya T, Morrison SJ, Clarke MF, Weissman IL. Stem cells, cancer, and cancer stem cells. Nature. 2001; 414(6859): 105-11.

20. Khodarev NN, Pitroda SP, Beckett MA, MacDermed DM, Huang L, Kufe DW, Weichselbaum RR. MUC1-induced transcriptional programs associated with tumorigenesis predict outcome in breast and lung cancer. Cancer Res. 2009; 69(7): 2833-7. Epub 2009 Mar 24.

21. Bölke E, Peiper M, Budach W, Matuschek C, Schwarz A, Orth K, Gripp S. (2007) Unilateral keloid formation after bilateral breast surgery and unilateral radiation Eur J Med Res. 12: 320-322

22. Matthaei H, Boelke E, Eisenberger CF, Alldinger I, Krieg A, Schmelzle M, Poremba C, Schellhammer F, Knoefel WT, Budach W, Peiper M (2008). Interdisciplinary treatment of primary hepatic angiosarcoma: emergency tumor embolization followed by elective surgery. Eur J Med Res. 4: 591-594

23. Matthaei H, Bölke E, Schmelzle M, Budach W, Orth K, Engers R, Cohnen M, Matuschek C, Gripp S, Knoefel WT, Peiper M (2008). Modern therapy of rectal carcinoma. Eur J Med Res. 13: 139-146

24. Peiper M, Bölke E, Orth K, Hosch SB, Rehders A, Matthaei A, Knoefel WT (2007) Current status of radical systematic lymphadenectomy in pancreatic cancer review of the literature Eur J Med Res. 12: 1-7

Received: June 18, 2009 / Accepted: July 22, 2009

Address for correspondence:

Privatpraxis

Univ.-Prof. Dr.med. Hans Bojar

Hans-Günther-Sohl-Str. 12

40235 Düsseldorf

Germany

Tel.: $\quad+49(0) 211 / 91312220$

Fax: $\quad+49(0) 211 / 91312222$

E-mail: info@prof-bojar.de 